\title{
Ascribed gender and characteristics of a visually androgynous Teachable Agent
}

\author{
Camilla Kirkegaard ${ }^{1}$, Betty Tärning ${ }^{2}$, Magnus Haake², \\ Agneta Gulz ${ }^{1}$, Annika Silvervarg ${ }^{1}$ \\ ${ }^{1}$ Dept. Computer and Information Science, Linköping University, Linköping, Sweden \\ \{camilla.kirkegaard, agneta.gulz, annika.silvervarg\}@liu.se \\ ${ }^{2}$ Cognitive Science, Lund University, Kungshuset, Lundagård, Lund, Sweden \\ \{betty.tarning, magnus.haake\} @lucs.lu.se
}

\section{Introduction}

This paper explores how users ascribe gender to a visually androgynous teachable agent, and if and how the ascribed gender can influence the perceived personality characteristics of the agent. Previous studies have shown positive effects of using agents with more neutral or androgynous appearances, for instance, a more gender neutral agent evoked more positive attitudes on females than did a more stereotypical female agent [1] and that androgynous agents are less abused than female agents [2]. Another study showed that even though an agent was visually androgynous, the user typically ascribed a gender to it [3].

We wanted to further explore the use of visually androgynous agents where the user can choose to ascribe them a gender, and how the ascribed gender affects how the agent is perceived. A pilot study was conducted in a Swedish primary school with 11-year olds, 21 girls and 16 boys. The agent used in this study was a teachable agent (TA), acting as a tutee in an educational software for learning history. The TA, see Fig 1. portrayed as a time elf, needs help to learn about history in order to succeed as the new "Guardian of Time". The students can teach the TA using different teaching activities as well as asking the TA to take tests in order to receive feedback on how well they have taught their TA.

\section{Study}

The study consisted of two 30 minutes sessions. During these sessions, the participants were instructed to teach their TA to help it pass tests in the learning environment. After completing the second session, the students were given a questionnaire regarding their experience with the digital learning environment and how they perceived the time elf (their TA). One questionnaire item addressed the perceived gender of the TA with the following five answer options: absolutely like a girl, a little like a girl, neither girl nor boy, a little like a boy, absolutely like a boy. The questionnaire also contained a list of 

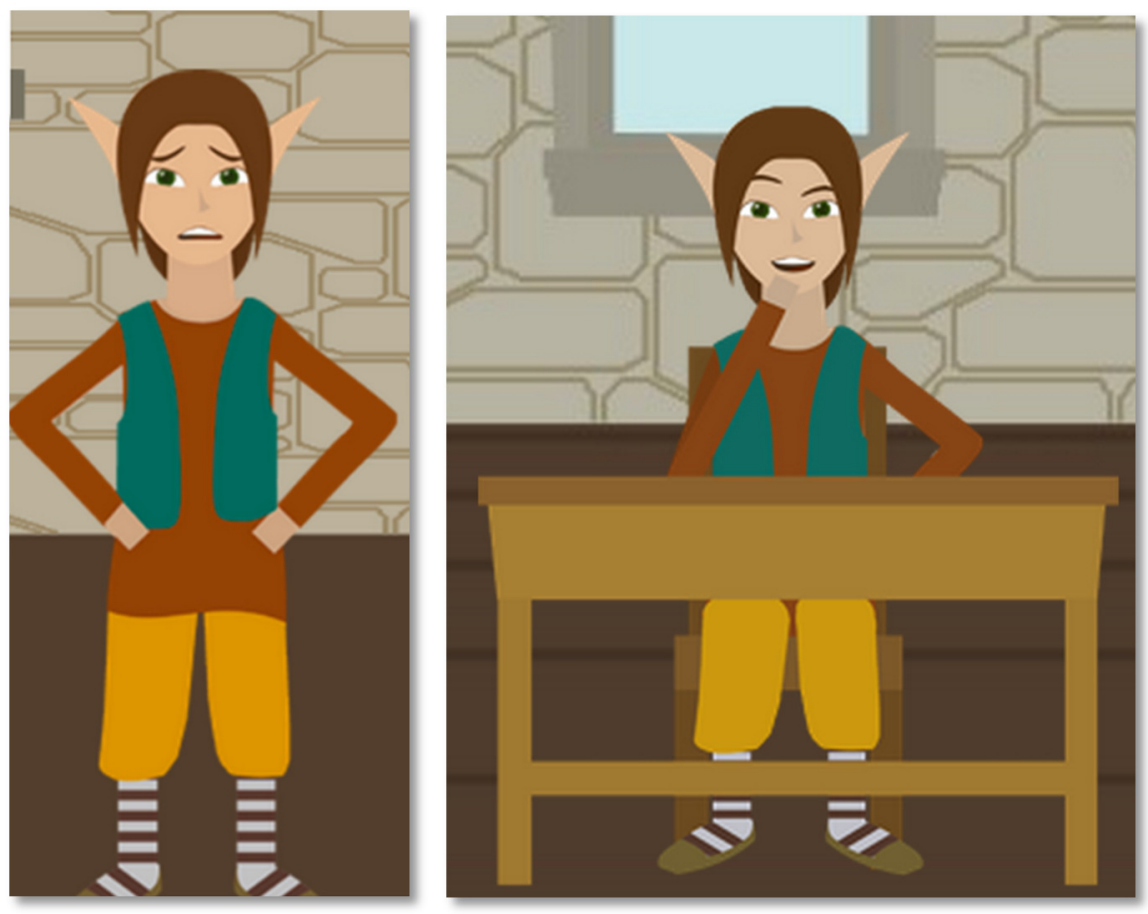

Fig. 1. The visually androgynous teachable agent in two different emotional states, unhappy to the left and eager to learn to the right.

personality related words (adjectives) and the students were asked to mark the ones they thought could be applied to the time elf (TA). The list of words was created by including words from the TIPI test, a 10-item measure of the Big Five (or Five-Factor Model) dimensions [4] and words related to intelligence, politeness, and naturalness. Half of the adjectives were positive words, i.e. friendly, dependable, self-disciplined, curious, caring, funny, sympathetic, warm, self-confident, intelligent, clever and natural; the rest were negative ones, i.e. shy, forgetful, disorganized, quarrelsome, critical, timid, stupid, easy-to-fool, mean, unkind, selfish, and unnatural.

We wanted to explore whether or not we would find a characteristics bias based on the ascribed gender. The previous mentioned study by Gulz and Haake [1] showed, for example, that a female ECA typically were described with less positive words than the male version, but those studies were conducted with visually stereotypical attributes. Would a visually androgynous ECA generate the same response based on the genders ascribed by the students?

The number of participant in this pilot study were quite few, why the participants were only allocated into two main groups: the group where the TA was perceived as "absolutely like a girl" or "a little like a girl" $(\mathrm{N}=9)$ and the group that perceived the TA as "absolutely like a boy" or "a little like a boy" $(\mathrm{N}=21)$. 


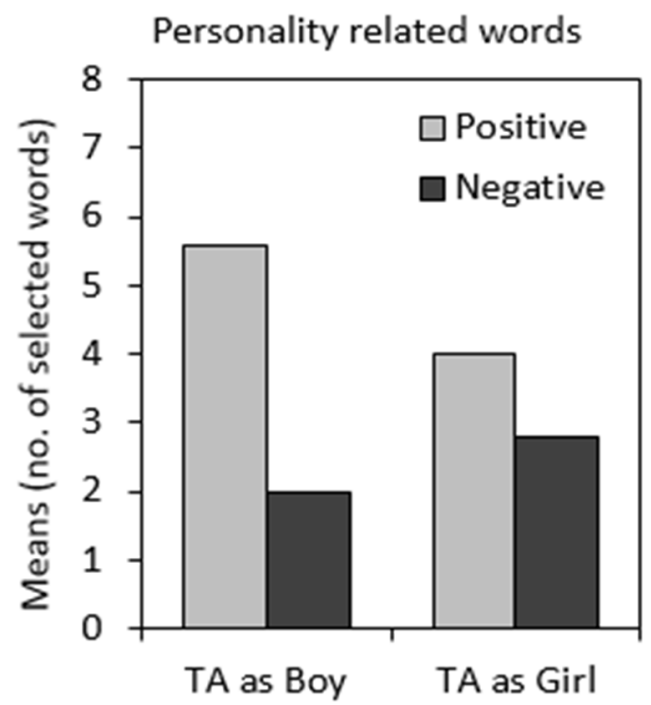

Fig. 2. Agents perceived as male are described with more positive and fewer negative words, than agents perceived as female.

An overall observation was that in the entire group, 69\% (153 of 220) of the characteristics ascribed to the TAs (disregarding ascribed gender) were positive. What is more interesting, however, is that when the TA is perceived as a boy the students seem to describe it with more positive words, with a mean of 5,6 positive words and a mean of 2,0 , negative words compared to when it is perceived as a girl, which received a mean of 4,0 positive words and a mean of 2,8 negative words, see Fig. 2. A Chi square test on the chosen words indicated a significant difference between the characteristics given to the TA perceived as a boy compared to when it was perceived as a girl $\left(X^{2}(1,220)=4.42, \mathrm{p}<.05\right)$.

Looking more closely at the difference in word distributions a Chi square test also showed that there was a significant difference between the distribution of positive and negative words with regard to ascribed gender of the TA in combination with the gender of the students $\left(X^{2}(1,220)=11.35, \mathrm{p}<.01\right)$. The TA perceived as a boy received a mean of 6,1 positive words and 1,3 negative words, while it received a mean of 4,9 positive and 3,0 negative words from the boys. For the agent perceived as a girl the corresponding numbers were a mean of 3,7 positive words and a mean of 2,3 negative words from the girls, and a mean of 5,0 positive words and a mean of 4,5 negative words from the boys, see Fig. 3.

\section{Conclusion and Discussion}

Previous studies have shown that an agent's appearance can influence how it is perceived and that female agents typically are subjected to more negative descriptions and abuse $[2,5]$. In this pilot study we found the same pattern, namely that the TA that was 
perceived as a girl received fewer positive words and more negative words than the same TA when it was perceived as a boy. We are aware that the number of students in this study is small and we intend to follow up with a large scale study looking deeper into this question and also relating it to how well the agent actually did perform in the learning environment. We will also revise the appearance of the agent to make it more androgynous since it was a shift towards more often ascribing it a male gender

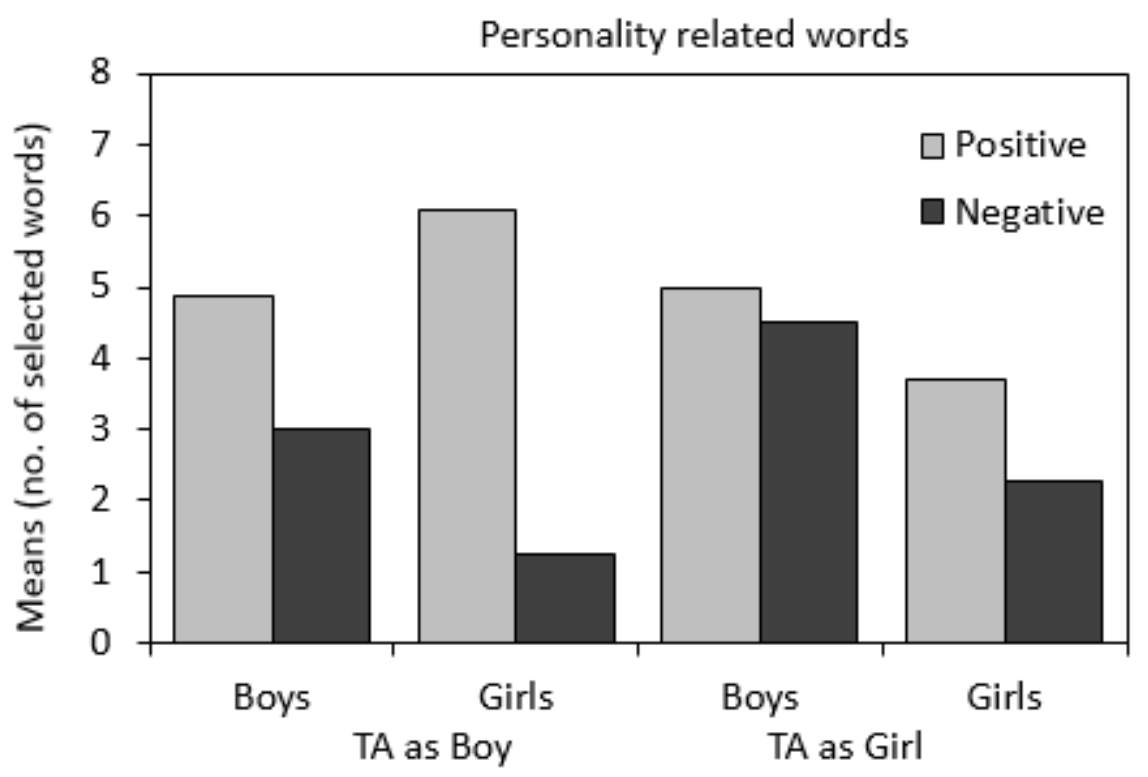

Fig. 3. The difference in words used to describe agents perceived as male versus female differ for female students from male students, especially for agents perceived as male.

\section{References}

1. Gulz, A., Haake, M.: Challenging Gender Stereotypes Using Virtual Pedagogical Characters. In: Goodman, S., Booth, S., Kirkup, G. (eds.) Gender Issues in Learning and Working with IT: Social Constructs and Cultural Contexts, pp. 113-132. IGI Global, Hershey (2010)

2. Silvervarg, A., Raukola, K., Haake, M., Gulz, A.: The Effect of Visual Gender on Abuse in Conversation with ECAs. In: Proc.of IVA 2012. LNCS, vol. 7502, pp 153-160 (2012)

3. Silvervarg, A., Haake, M., Gulz, A.: Educational Potentials in Visually Androgynous Pedagogical Agents. In: Proc of AIED 2013., LNCS, vol. 7926, pp. 599-602 (2013)

4. Gosling, S. D., Rentfrow, P. D., Jr. Swann, W. B.: A very brief measure of the big five personality domains. Journal of Research in Personality 37, 504--528 (2003)

Veletsianos, G., Scharber, C. Doering, A.: When Sex, Drugs, and Violence Enter the Classroom: Conversations Between Adolescent Social Studies Students and a Female Pedagogical Agent. Interact. Compu. 20(3), pp. 292-301 (2008) 